\title{
Effects of $\beta$-caryophyllene on arginine ADP-ribosyltransferase 1-mediated regulation of glycolysis in colorectal cancer under high-glucose conditions
}

\author{
LI ZHOU*, MU-LU ZHAN", YI TANG*, MING XIAO, MING LI, QING-SHU LI, \\ LIAN YANG, XIAN LI, WEN-WEN CHEN and YA-LAN WANG \\ Department of Pathology, Molecular Medicine and Cancer Research Center, \\ Chongqing Medical University, Chongqing 400016, P.R. China
}

Received January 4, 2018; Accepted May 31, 2018

DOI: 10.3892/ijo.2018.4506

\begin{abstract}
Type 2 diabetes mellitus (T2DM) is associated with an increased risk of the development of colorectal cancer (CRC). A previous study revealed that the levels of arginine-specific mono-ADP-ribosyltransferase 1 (ART1) in CRC tissues from patients with T2DM were higher than in non-diabetic patients. Hyperglycemia, which is a risk factor of cancer, is a common feature of T2DM; however, the effects of ART1 on glycolysis and energy metabolism in CRC cells under highglucose conditions remains to be elucidated. $\beta$-caryophyllene (BCP) has been reported to exert anticancer and hypoglycemic effects. In the present study, CT26 cells were cultured under a high-glucose conditions and the expression levels of relevant factors were detected by western blotting. Cell Counting Kit-8 assay, flow cytometry, Hoechst 33258 staining, ATP assay and lactic acid assay were used to detect the proliferation, apoptosis and energy metabolism of CT26 cells. To observe the effects of ART1 and BCP on tumor growth in vivo, CT26
\end{abstract}

Correspondence to: Professor Ya-Lan Wang, Department of Pathology, Molecular Medicine and Cancer Research Center, Chongqing Medical University, 1 Yixueyuan Road, Yuzhong, Chongqing 400016, P.R. China

E-mail: wangyalan074@126.com

*Contributed equally

Abbreviations: ART1, arginine-specific mono-ADP-ribosyltransferase 1; ATP, adenosine triphosphate; BCP, $\beta$-caryophyllene; CB2, cannabinoid receptor 2; CRC, colorectal cancer; HIF-1 $\alpha$, hypoxiainducible factor $1 \alpha$; IGF1, insulin-like growth factor 1; LDHA, lactate dehydrogenase A; MAPK, mitogen-activated protein kinase; NA, nicotinamide; p-AKT, phosphorylated-AKT; PDK1, pyruvate dehydrogenase kinase 1; PDTC, pyrrolidinedithiocarbamic acid; T2DM, type 2 diabetes mellitus; STZ, streptozocin

Key words: ART1, $\beta$-caryophyllene, colorectal cancer, hyperglycemia cell tumors were successfully transplanted into BALB/c mice with T2DM. The results demonstrated that overexpression of ART1 may increase glycolysis and energy metabolism in CT26 CRC cells under high glucose conditions by regulating the protein kinase $\mathrm{B} / \mathrm{mammalian}$ target of rapamycin/c-Myc signaling pathway and the expression of glycolytic enzymes. BCP inhibited the effects induced by ART1, which may be due to a BCP-induced reduction in the expression levels of ART1 via nuclear factor- $\kappa \mathrm{B}$. Therefore, ART1 may be considered a therapeutic target for the treatment of diabetic patients with CRC.

\section{Introduction}

Type 2 diabetes mellitus (T2DM) has been reported to increase the risk of various types of cancer, including colorectal cancer (CRC) (1-3). A low survival rate is evident in diabetic patients with CRC, even in patients that have undergone complete curative surgical treatment for CRC (4). Hyperglycemia is one of the most direct internal environmental alterations in patients with T2DM $(5,6)$. It has previously been demonstrated that hyperglycemia is a key factor in the mechanisms underlying diabetes-associated increased cancer risk (7). Furthermore, hyperglycemia activates numerous pathways to promote the progression of cancer; for example, it increases the levels of insulin-like growth factor 1 (IGF1), upregulates protein kinase $\mathrm{B}(\mathrm{AKT}) /$ mammalian target of rapamycin (mTOR) signaling and enhances $\mathrm{WNT} / \beta$-catenin signaling (8). Therefore, identifying the factor that affects the glycolytic pathway in CRC may help to increase the survival rate of diabetic patients with CRC.

Our previous studies demonstrated that arginine-specific mono-ADP-ribosyltransferase 1 (ART1) promotes proliferation, invasion and metastasis of $\mathrm{CRC}$ in vitro and in vivo $(9,10)$. Upregulation of the expression of ART1 activates the Ras homologue gene family mer A/ROCK1 pathway, which affects the expression of phosphorylated-AKT (p-AKT), $\mathrm{c}-\mathrm{Fos}$ and c-Myc, and promotes the proliferation and invasion of CRC cells (9). Furthermore, ART1 upregulates hypoxia- 
inducible factor $1 \alpha(\mathrm{HIF}-1 \alpha)$ via the phosphoinositide 3-kinase (PI3K)/AKT signaling pathway, in order to promote the expression of angiogenic factors, such as vascular endothelial growth factor and basic fibroblast growth factor, and to enhance angiogenesis in cancer tissue (11). It has also been revealed that the expression levels of ART1 are higher in CRC tissues from patients with T2DM compared with in nondiabetic CRC tissues. Furthermore, overexpression of ART1 can increase the growth of transplanted CT26 tumors in streptozocin (STZ)-induced diabetic Balb/c mice (Chen et al, unpublished data). These findings indicated that ART1 may be associated with glycolysis in CRC; however, the mechanism remains unclear. It is well known that tumor cells rely on increasing aerobic glycolysis to obtain energy, in which glycolytic enzymes serve a significant role; these enzymes include pyruvate dehydrogenase kinase 1 (PDK1) and lactate dehydrogenase A (LDHA) (12-14). In addition, c-Myc may regulate aerobic glycolysis through acting on metabolic enzymes, including hexokinase 2, LDHA and PDK1 (15). However, to the best of our knowledge, the effects of ART1 on the expression of glycolytic enzymes have yet to be determined. In the present study, the expression levels of AKT/mTOR, c-Myc and the downstream glycolytic enzymes PDK1 and LDHA were detected, and the generation of adenosine triphosphate (ATP) and lactic acid were measured, in order to investigate whether ART1 could regulate glycolytic enzymes via the AKT/mTOR/ c-Myc pathway and thus modulate the generation of ATP and lactic acid.

$\beta$-caryophyllene (BCP), which is a natural sesquiterpene obtained from spices, is present in numerous plants worldwide, including Syzygium aromaticum and Cinnamomum cassia. It has been reported that BCP possesses significant anticancer activities by affecting the growth and proliferation of numerous types of cancer cell (16). In addition, BCP may inhibit the proliferation of HCT-116 and HT-29 CRC cells. BCP can bind to cannabinoid receptor 2 (CB2), thus stimulating mitogen-activated protein kinase (MAPK) and inactivating the PI3K/AKT/mTOR pathway, in order to suppress tumor growth and promote tumor apoptosis (17). Furthermore, BCP has a beneficial effect on glucose homeostasis by increasing the secretion of insulin and restoring glucose homeostasis in diabetic rats (18); therefore, BCP exerts both hypoglycemic and antitumor effects. The present study hypothesized that, if ART1 could regulate the glycolytic process via the AKT/mTOR/c-Myc pathway, BCP may inhibit ART1-regulated glycolysis through interfering with this pathway. Therefore, the present study assessed the effects of $\mathrm{BCP}$ on glycolysis and its underlying mechanism in CRC in response to ART1 overexpression.

\section{Materials and methods}

Cells and reagents. The CT26 cell line was provided by Professor Y.Q. Wei (Sichuan University, Chengdu, China). ART1-cDNA, untransfected, lentivirus (LV)-control and ART1-short hairpin (sh)RNA CT26 cell lines were established in previous experiments $(19,20)$. The experimental groups were as follows: ART1-cDNA group, CT26 cells in which ART1 was overexpressed; ART1-shRNA group, CT26 cells in which ART1 was silenced; untransfected group, untransfected CT26 cells; LV-control group, CT26 cells which were transfected with an empty LV vector. The untransfected and LV-control groups were considered the control groups. To detect the effects of BCP (Sigma-Aldrich; Merck KGaA, Darmstadt, Germany) on ART1-induced glycolysis, ART1-cDNA CT26 cells were incubated under high-glucose conditions $(25 \mathrm{mM})$ at $37^{\circ} \mathrm{C}$ for $48 \mathrm{~h}$ in the control group. In the experimental groups, ART1-cDNA CT26 cells were treated with glucose $(25 \mathrm{mM})$ and $50 \mu \mathrm{M}$ BCP [dissolved in $0.1 \%$ dimethyl sulfoxide (DMSO) (D-5879, Sigma-Aldrich, Merck KGaA)] at $37^{\circ} \mathrm{C}$ for $48 \mathrm{~h}$. glucose $(25 \mathrm{mM})$ and $0.1 \%$ DMSO at $37^{\circ} \mathrm{C}$ for $48 \mathrm{~h}$, or glucose $(25 \mathrm{mM})$ and $10 \mu \mathrm{M}$ pyrrolidinedithiocarbamic acid (PDTC) at $37^{\circ} \mathrm{C}$ for $48 \mathrm{~h}$. Each group of CT26 cells was cultured in RPMI-1640 medium (HyClone; GE Healthcare Life Sciences, Logan, UT, USA) supplemented with $10 \%$ fetal bovine serum (Pan-Biotech $\mathrm{GmbH}$, Aidenbach, Germany), $100 \mu \mathrm{g} / \mathrm{ml}$ streptomycin and $100 \mathrm{U} / \mathrm{ml}$ penicillin (Beyotime Institute of Biotechnology, Shanghai, China) at $37^{\circ} \mathrm{C}$ in an incubator containing $5 \% \mathrm{CO}_{2}$. Cells were cultured in the presence of glucose (25 mM) (21) in complete culture medium for $48 \mathrm{~h}$. The bicinchoninic acid (BCA) protein assay kit, Hoechst staining kit, adenosine triphosphate (ATP) assay kit and PDTC were purchased from Beyotime Institute of Biotechnology. The lactic acid assay kit was purchased from Nanjing Jiancheng Bioengineering Institute (Nanjing, China). STZ and nicotinamide (NA) were purchased from Sigma-Aldrich; Merck KGaA.

Western blot analysis. Cells from each group were collected following exposure to high-glucose conditions. Total protein was extracted using whole-cell lysis buffer (Beyotime Institute of Biotechnology). In addition, the subcutaneous tumors were cut into small pieces, weighed, homogenized and then lysed with radioimmunoprecipitation assay lysis buffer (Beyotime Institute of Biotechnology; $100 \mu \mathrm{l} / 10 \mathrm{mg}$ ) for $30 \mathrm{~min}$ on ice. The lysate was transferred into a $1.5 \mathrm{ml}$ centrifuge tube and centrifuged at $16,099 \mathrm{x}$ g for $5 \mathrm{~min}$ at $4^{\circ} \mathrm{C}$. Protein concentrations were evaluated using the BCA protein assay kit (Beyotime Institute of Biotechnology). Proteins (20 $\mu \mathrm{g}$ total protein/well) were separated by $8-10 \%$ SDS-PAGE and were then transferred onto polyvinylidene fluoride membranes (EMD Millipore, Billerica, MA, USA). The membranes were then incubated at room temperature for $2 \mathrm{~h}$ in a blocking solution; 5\% bovine serum albumin (0332; Amresco LLC, Solon, OH, USA) in Tris-buffered saline containing $0.1 \%$ Tween-20 (TBST) was used when phosphorylated proteins were to be detected, whereas 5\% non-fat milk in TBST was used when unphosphorylated proteins were to be detected. Once the membranes had been washed in TBST, they were incubated with primary antibodies overnight at $4{ }^{\circ} \mathrm{C}$. The following primary antibodies (dilutions, 1:1,000) were used: AKT (\#4691T), phosphorylated (p)-AKT (ser473) (\#4060T), mTOR (\#2983P), p-mTOR (ser2448) (\#5536T), PDK1 (\#3062T), c-Myc (\#5605T), LDHA (\#3558S), B-cell lymphoma 2-associated X protein (Bax) (\#14796S) and cleaved caspase-3 (\#9664T) (all from Cell Signaling Technology, Inc., Danvers, MA, USA), ART1 (A10103; ABclonal, Inc., Woburn, MA, USA) and $\beta$-actin (bsm-33036M; BIOSS, Beijing, China). The membranes were washed three times with TBST, and were then incubated with secondary antibodies [peroxidase-conjugated goat anti-rabbit 
immunoglobulin (Ig)G (1:2,000, AS014; ABclonal, Inc.) or peroxidase-conjugated goat anti-mouse IgG (1:2,000, AS003, ABclonal, Inc.) for $2 \mathrm{~h}$ at room temperature. Subsequently, the membranes were washed with TBST three times. Blots were visualized and images were captured using a ChemiDoc XRS system (Bio-Rad Laboratories, Inc., Hercules, CA, USA) and chemiluminescence (BeyoECL Plus; Beyotime Institute of Biotechnology). All experiments were repeated in triplicate.

Cell survival assay. ART1-cDNA CT26 cells were seeded in 96-well plates at a density of $1 \times 10^{4}$ cells/well. After $24 \mathrm{~h}$, the cells were exposed to increasing concentrations of $\mathrm{BCP}(0,5$, $10,20$ and $50 \mu \mathrm{M})$ and a high concentration of glucose $(25 \mathrm{mM})$ for 24, 48 and 72 h. Cell Counting Kit-8 (CCK-8) (7sea Biotech, Shanghai, China) reagent (10 $\mu \mathrm{l})$ was added to each plate and the cells were incubated for $1 \mathrm{~h}$ at $37^{\circ} \mathrm{C}$. The absorbance was recorded using a microplate reader (BioTek Instruments, Inc., Winooski, VT, USA) at an optical density (OD) of $450 \mathrm{~nm}$. The percentage of inhibition was calculated using the following formula: [1 - (mean OD of experimental group - mean OD of blank control group) / (mean OD of control group - mean OD of blank control group)] x $100 \%$. The percentage of proliferation was calculated using the formula: [(mean OD of experimental group - mean OD of control group) / mean OD of control group] x $100 \%$.

ATP content assay. To measure glycolysis-mediated production of ATP, cells were cultured in a 6-well plate and treated with a high concentration of glucose $(25 \mathrm{mM})$ and BCP $(50 \mu \mathrm{M})$ for $48 \mathrm{~h}$. Cellular ATP levels were measured using a firefly luciferase-based ATP assay kit (cat. no. S0026; Beyotime Institute of Biotechnology). Briefly, protein was suspended in standard reaction buffer containing luciferin and luciferase, and was then assessed according to the manufacturer's protocol. Luminescence was measured using a Glomax ${ }^{\circledR}$ Multi Detection system (Promega Corporation, Madison, WI, USA).

Lactic acid measurement. ART1-cDNA CT26 cells in a 6-well plate were incubated with or without BCP $(50 \mu \mathrm{M})$ under high-glucose $(25 \mathrm{mM})$ conditions at $37^{\circ} \mathrm{C}$ and $5 \% \mathrm{CO}_{2}$ for $48 \mathrm{~h}$. The supernatant was then collected into Eppendorf tubes and centrifuged at $111.8 \mathrm{x}$ g for $5 \mathrm{~min}$. The amount of lactic acid in the supernatant was determined using a lactic acid test kit (A019-2; Nanjing Jiancheng Bioengineering Institute), according to the manufacturer's protocol.

Staining with Hoechst 33258. ART1-cDNA CT26 cells were cultured in 6-well plates (1x10 cells/well) under high-glucose conditions $(25 \mathrm{mM})$ in the presence or absence of BCP $(50 \mu \mathrm{M})$ at $37^{\circ} \mathrm{C}$ and $5 \% \mathrm{CO}_{2}$ for $48 \mathrm{~h}$. After removal of the culture medium, the cells were fixed $4 \%$ paraformaldehyde $(0.5 \mathrm{ml})$ for $10 \mathrm{~min}$ and washed twice with PBS. After treatment with Hoechst $33258(0.5 \mathrm{ml})$ for $5 \mathrm{~min}$ in the dark, stained nuclei were observed under a fluorescence microscope (ZOE ${ }^{\mathrm{TM}}$ Fluorescent Cell Imager; Bio-Rad Laboratories, Inc.). The apoptotic ratio (AR) was calculated using the following formula: $\mathrm{AR}=$ [apoptotic cells / total cell count $] \times 100 \%$.

Flow cytometry. ART1-cDNA CT26 cells were seeded in 6 -well plates $\left(1 \times 10^{5}\right.$ cells/well) and were cultured with a high concentration of glucose $(25 \mathrm{mM})$ in the presence of absence of $\mathrm{BCP}(50 \mu \mathrm{M})$ at $37^{\circ} \mathrm{C}$. After being cultured for $48 \mathrm{~h}$, suspended and adherent cells were collected by centrifugation (111.8 x g for $5 \mathrm{~min})$, washed twice with PBS and resuspended in binding buffer ( $70 \%$ ethanol) prior to centrifugation at $111.8 \mathrm{x} \mathrm{g}$ for $5 \mathrm{~min}$. Subsequently, the collected cells were treated with RNase A $(10 \mathrm{~g} / \mathrm{ml}$; cat. no. 2158; Takara Biotechnology Co., Ltd., Dalian, China) for $1 \mathrm{~h}$ at $37^{\circ} \mathrm{C}$ and were then treated with $50 \mathrm{mg} / \mathrm{ml}$ propidium iodide (PI; cat.no. P1304MP; Thermo Fisher Scientific, Inc.) overnight at $4^{\circ} \mathrm{C}$ before flow cytometry (FACSVantage SE; BD Biosciences, Franklin Lakes, NJ, USA). The proliferation index (PI) was measured according to the following formula: $\mathrm{PI}=(\mathrm{G} 2+\mathrm{S}) /(\mathrm{G} 1+\mathrm{S}+\mathrm{G} 2)$. Apoptosis was evaluated using the Annexin V-fluorescein isothiocyanate Apoptosis Detection kit (C1062; Beyotime Institute of Biotechnology), according to the manufacturer's protocol for flow cytometry (FACSVantage SE; BD Biosciences). The apoptotic percentage was determined as follows: Apoptotic rate $(\%)=[$ apoptotic cells $(\mathrm{A}) /$ total cell count $(\mathrm{T})] \mathrm{x} 100$.

Establishment of the animal model. The present study was approved by the ethics committee of Chongqing Medical University (Chongqing, China). Adult male Balb/c mice ( $\mathrm{n}=48$; weight, $25 \pm 2 \mathrm{~g}$; age, 6-8 weeks) were obtained from the Experimental Animal Center of Chongqing Medical University. They were maintained under optimal conditions (12-h light/ dark cycle; humidity, $60 \pm 5 \%$; temperature, $22 \pm 3^{\circ} \mathrm{C}$; free access to food and water). Mice were injected intraperitoneally (i.p.) with STZ (STZ in $0.1 \mathrm{M}$ citric acid buffer, $\mathrm{pH} 4.5 ; 100 \mathrm{mg} / \mathrm{kg}$ on days 1 and 3 ) after being fasted for $16 \mathrm{~h}$ (with free access to water). NA in saline $(120 \mathrm{mg} / \mathrm{kg})$ was injected i.p. $15 \mathrm{~min}$ prior to the administration of STZ (22). The weight of each mouse and the concentration of glucose in the blood were measured to ensure that the diabetic mouse model was properly established. Subsequently, CT26 cells were harvested from each of the four cell groups; a 200- $\mu$ l single cell suspension containing $2 \times 10^{6}$ cells was injected into the right forelimb of diabetic $\mathrm{Balb} / \mathrm{c}$ mice to establish the CT26 transplanted tumor model for 14 days in diabetic Balb/c mice. In addition, BCP was dissolved in corn oil and administered intragastrically $(200 \mathrm{mg} / \mathrm{kg}$ body weight/day) (18). In the ART1-cDNA + BCP group, diabetic $\mathrm{Balb} / \mathrm{c}$ mice, which had been inoculated with ART1-cDNA CT26 cells for 10 days, were treated with BCP. The same dose of corn oil was administered intragastrically to diabetic Balb/c mice inoculated with ART1-cDNA CT26 cells to generate the control group. Tumor volume was computed from diameters measured using a digital caliper, using the following formula: $\mathrm{V}=\mathrm{ab}^{2} / 2$, where a refers to the maximum diameter and $\mathrm{b}$ to the minimum diameter. Following sacrifice of the mice, all tumors were obtained and used for western blotting.

Statistical analysis. All experiments were conducted at least three times. Data were analyzed using SPSS 18.0 software (SPSS, Chicago, IL, USA). Data are presented as the means \pm standard deviation. Statistical analysis was performed using Student's t-test or one-way analysis of variance followed by the least significant difference test, which was used to analyze the ranked data and the differences between each group. $\mathrm{P}<0.05$ was considered to indicate a statistically significant difference. 

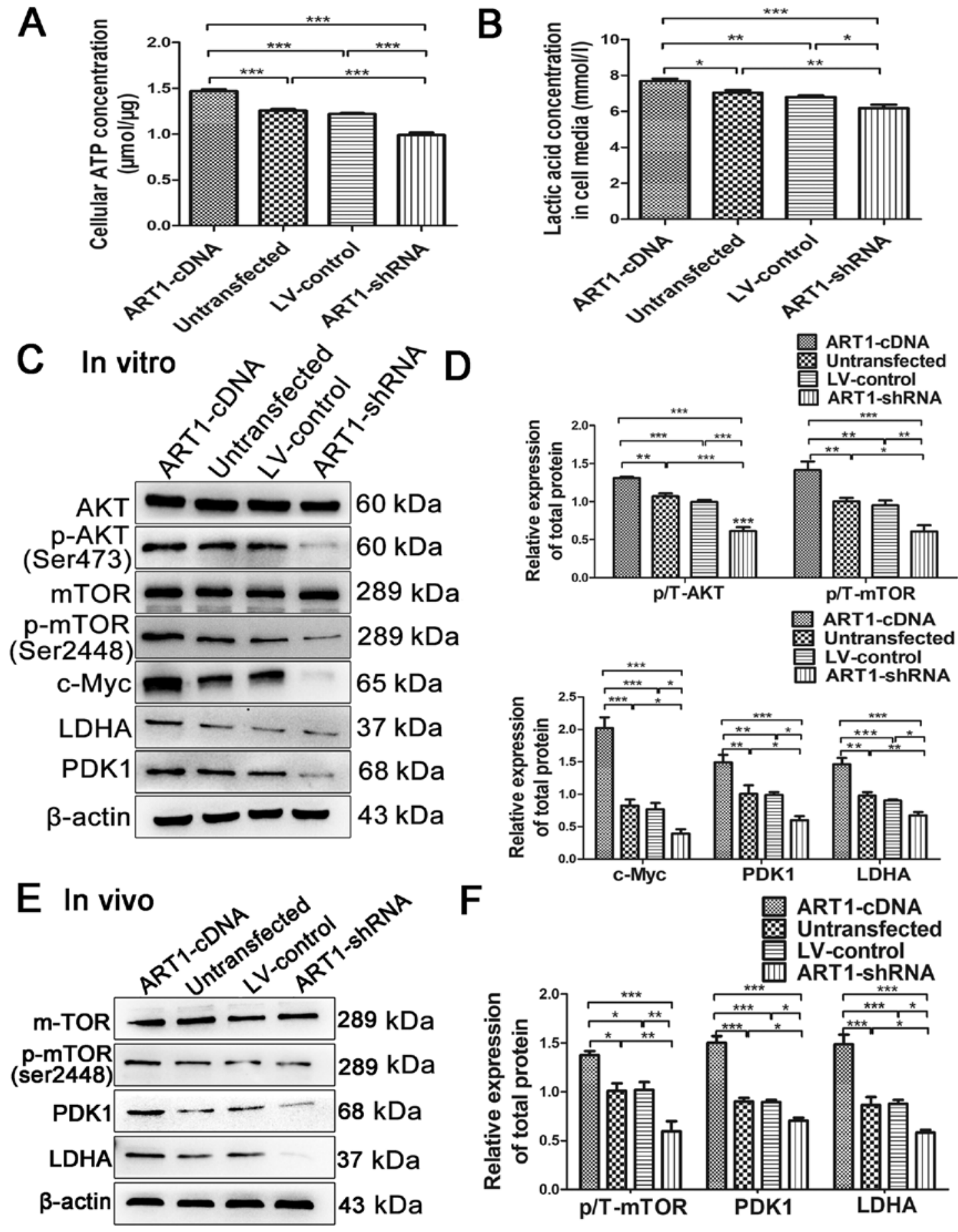

Figure 1. ART1 regulates the expression levels of glycolytic enzymes via AKT/mTOR. (A and B) Effects of ART1 on ATP and lactic acid concentrations were detected. (C and D) Effects of ART1 on the expression levels of AKT, p-AKT, mTOR, p-mTOR, c-Myc, LDHA and PDK1 in the ART1-cDNA, ART1-shRNA, LV-control and untransfected CT26 cells treated with high glucose $(25 \mathrm{mM})$ for $48 \mathrm{~h}$. (E and F) Effects of ART1 on the expression levels of mTOR, p-mTOR, LDHA and PDK1 in ART1-cDNA, ART1-shRNA, LV-control and untransfected CT26 cell tumors from diabetic Balb/c mice. ${ }^{*} \mathrm{P}<0.05,{ }^{* *} \mathrm{P}<0.01,{ }^{* * * *} \mathrm{P}<0.001$. AKT, protein kinase B; ART1, arginine-specific mono-ADP-ribosyltransferase 1; ATP, adenosine triphosphate; LDHA, lactate dehydrogenase; LV, lentivirus; mTOR, mammalian target of rapamycin; p-, phosphorylated; PDK1, pyruvate dehydrogenase kinase 1; shRNA, short hairpin RNA.

\section{Results}

Effects of ART1 on the generation of ATP and lactic acid in CT26 cells. Lactic acid and ATP concentrations were detected in the four cell groups under high-glucose conditions, in order to investigate whether ART1 regulates aerobic glycolysis through the generation of ATP and lactic acid. Compared with in the untransfected and LV-control groups, lactic acid and ATP concentrations were significantly increased in the ART1-cDNA group, whereas those in the ART1-shRNA group were decreased (Fig. 1A and B).

Effects of ART1 on the expression of AKT, $p$-AKT, mTOR, $p$-mTOR, $c-M y c$, PDKI and LDHA in vitro and in vivo. Each group was treated with high glucose for $48 \mathrm{~h}$, after which the expression levels of AKT, p-AKT, mTOR and p-mTOR 
A

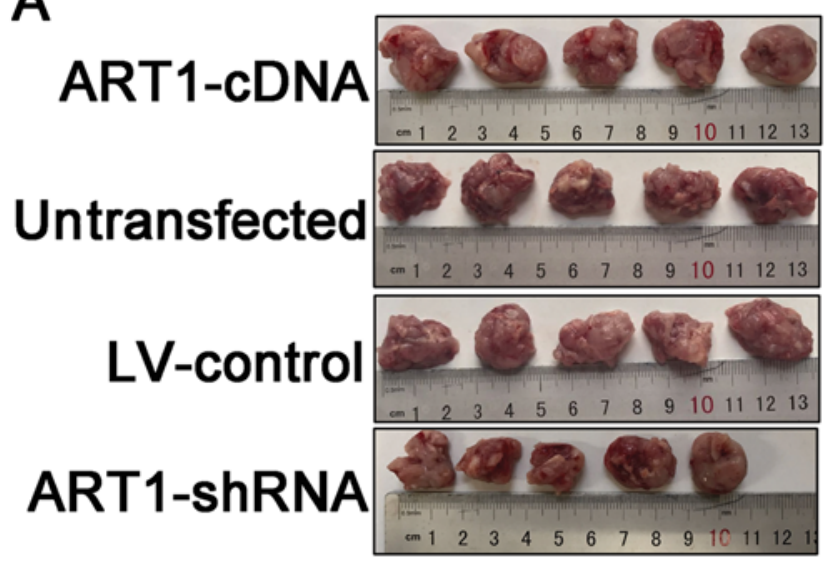

B

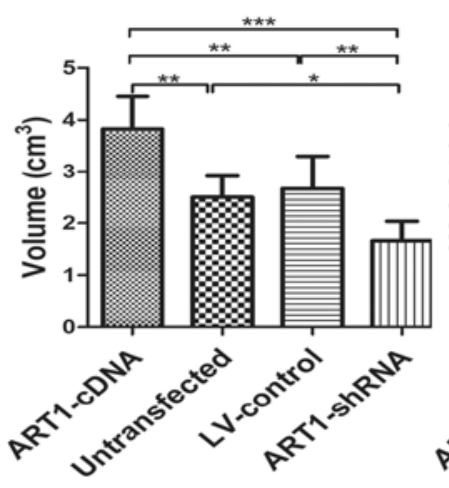

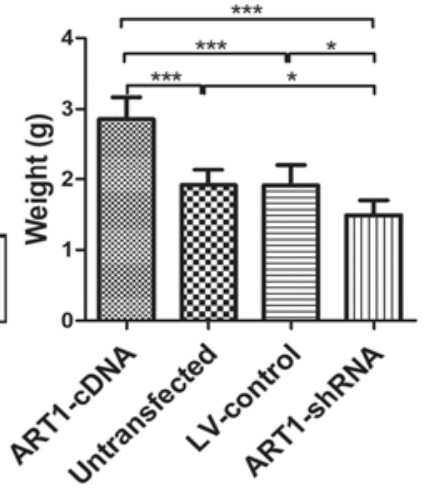

ART1-cDNA $\otimes$ Untransfected LV-control ART1-shRNA
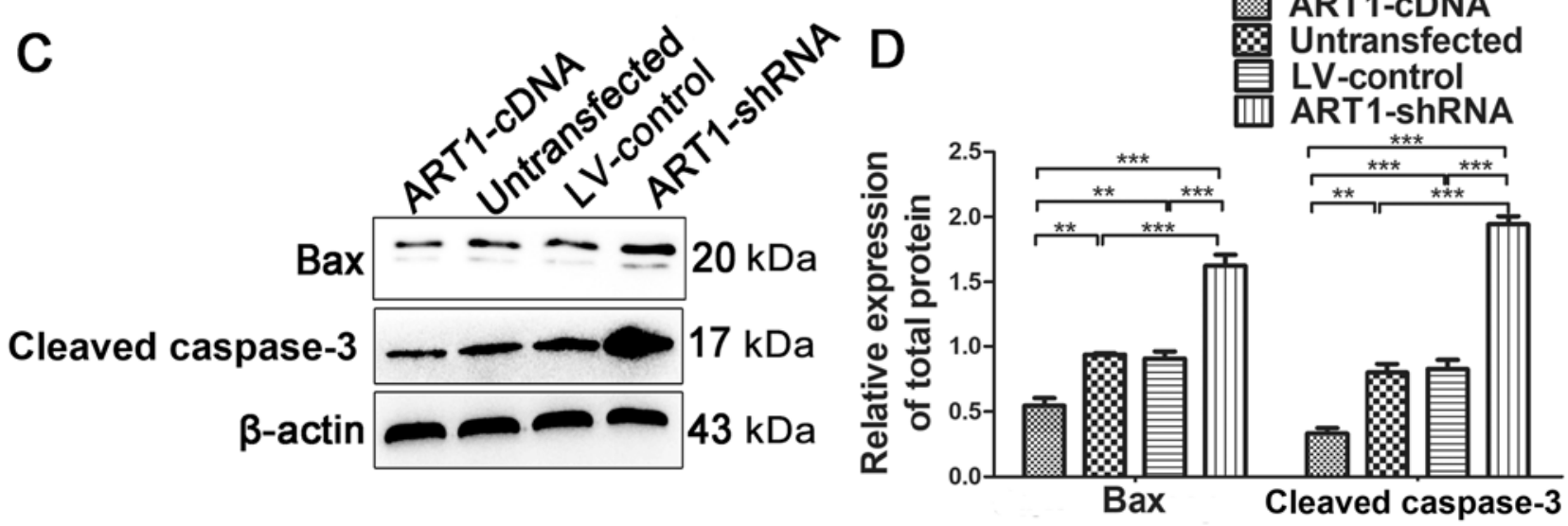

Figure 2. Effects of ART1 on CT26 tumor growth and cell apoptosis in diabetic Balb/c mice. (A) ART1-cDNA, untransfected, LV-control and ART1-shRNA CT26 cells were transplanted into diabetic Balb/c mice for 14 days. (B) Effects of ART1 on tumor weight and volume. (C and D) Effect of ART1 on the expression levels of Bax and cleaved caspase- 3 in each transplanted tumor. ${ }^{* *} \mathrm{P}<0.01,{ }^{* * *} \mathrm{P}<0.001$. ART1, arginine-specific mono-ADP-ribosyltransferase 1 ; Bax, B-cell lymphoma 2-associated X protein; LV, lentivirus; shRNA, short hairpin RNA.

were measured by western blotting. Compared with in the untransfected and LV-control groups, the expression levels of $\mathrm{p}-\mathrm{AKT} / \mathrm{AKT}$ and $\mathrm{p}-\mathrm{mTOR} / \mathrm{mTOR}$ were increased in the ART1-cDNA group; however, they were decreased in the ART1-shRNA group $(\mathrm{P}<0.01$; Fig. $1 \mathrm{C}$ and $\mathrm{D})$. The expression levels of c-Myc, PDK1 and LDHA were also significantly increased in the ART1-cDNA group and decreased in the ART1-shRNA group $(\mathrm{P}<0.05)$, indicating that ART1 may induce activation of c-Myc signaling cascades, thus affecting PDK1 and LDHA expression (Fig. 1C and D).

To confirm whether alterations in ART1 may affect the expression levels of mTOR, p-mTOR, PDK1 and LDHA, the expression levels of these proteins were detected in CT26 cell allograft transplanted tumors in diabetic Balb/c mice. The results demonstrated that the expression levels of p-mTOR, PDK1 and LDHA in the ART1-cDNA CT26 group were increased, whereas the expression levels of p-mTOR, PDK1 and LDHA were decreased in the ART1-shRNA group, as compared with in the untransfected and LV-control groups $(\mathrm{P}<0.05$; Fig. $1 \mathrm{E}$ and $F$ ). The expression levels of mTOR exhibited no significant difference in the four groups $(\mathrm{P}>0.05$; Fig. $1 \mathrm{E}$ and $\mathrm{F})$. These findings suggested that ART1 may impact glycolysis though regulating the AKT/mTOR molecular signal.

Effects of ART1 on the growth of CT26 cell allograft transplanted tumors in diabetic Balb/c mice. A total of 14 days after the CT26 cells were inoculated into diabetic Balb/c mice, tumor weight and volume were measured in each group. Compared with in the untransfected and LV-control groups, tumor weight and volume were significantly increased in the ART1-cDNA group and decreased in the ART1-shRNA group $(\mathrm{P}<0.01$; Fig. 2A and B). Furthermore, the expression levels of Bax and cleaved caspase-3, which are indicators of apoptosis, were decreased in the tumor tissues from the ART1-cDNA group and increased in the ART1-shRNA group, as compared with in the LV-control and untransfected groups $(\mathrm{P}<0.001$ Fig. 2C and D). These findings suggested that overexpression of ART1 may upregulate the growth and diminish cellular apoptosis of CT26 cell tumors in diabetic mice.

Effects of BCP on the proliferation and apoptosis of ART1cDNA CT26 cells. In order to investigate the effects of BCP (Fig. 3A) on the proliferation of ART1-cDNA CT26 cells, a CCK-8 assay was used to measure cellular viability. The results demonstrated that the inhibitory rate of ART1-cDNA CT26 cell proliferation was increased when cells were cultured with BCP $(50 \mu \mathrm{M})$ for $24 \mathrm{~h}(\mathrm{P}<0.001$; Fig. 3B). To further analyze this effect, ART1-cDNA CT26 cells cultured in high-glucose $(25 \mathrm{mM})$ were treated with $\mathrm{BCP}(50 \mu \mathrm{M})$ for $48 \mathrm{~h}$, in order to detect the effects of BCP on cell proliferation, cell cycle progression and apoptosis. The proliferative capacity of ART1-cDNA CT26 cells cultured with BCP was decreased 
A

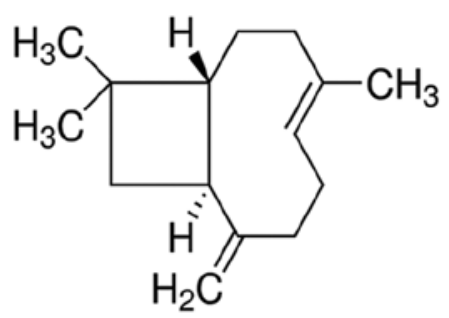

C

$\mathrm{H}_{2} \mathrm{C}$
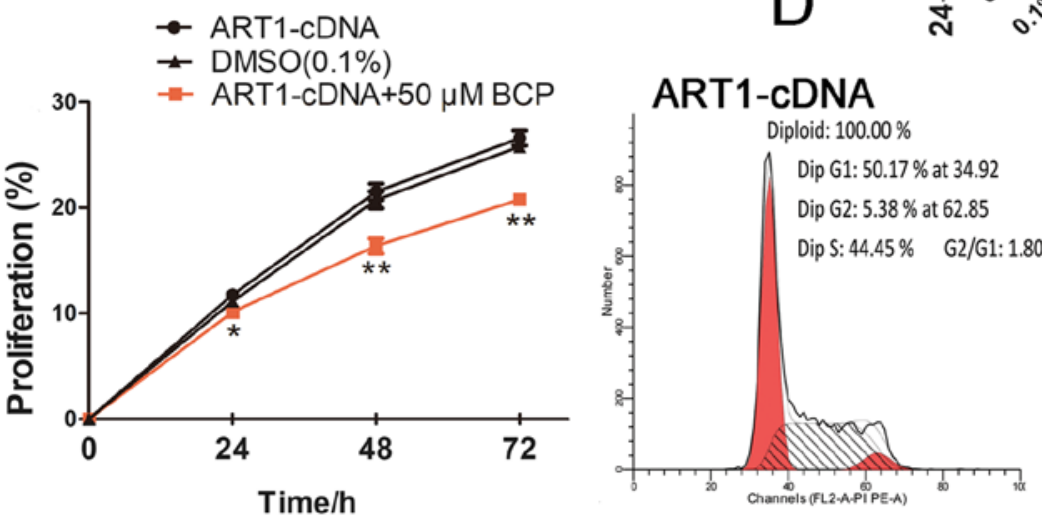

ART1-CDNA+50 $\mu \mathrm{M} B C P$

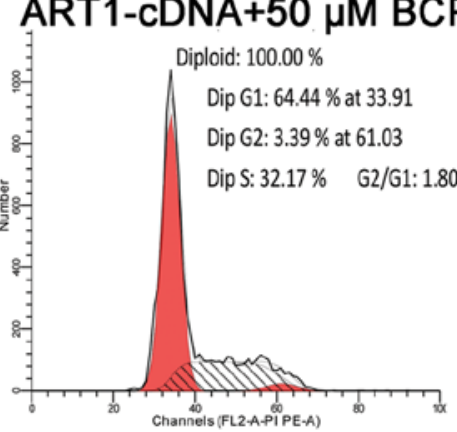

E

ART1-CDNA

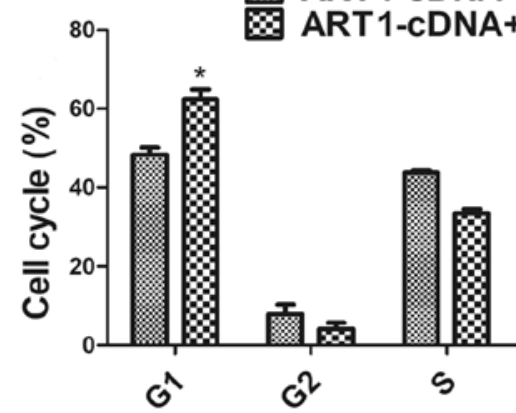

$\mathrm{F}$

ART1-CDNA

$\otimes$ ART1-CDNA+50 $\mu \mathrm{M} \mathrm{BCP}$

G ART1-cDNA

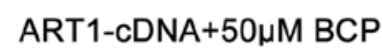
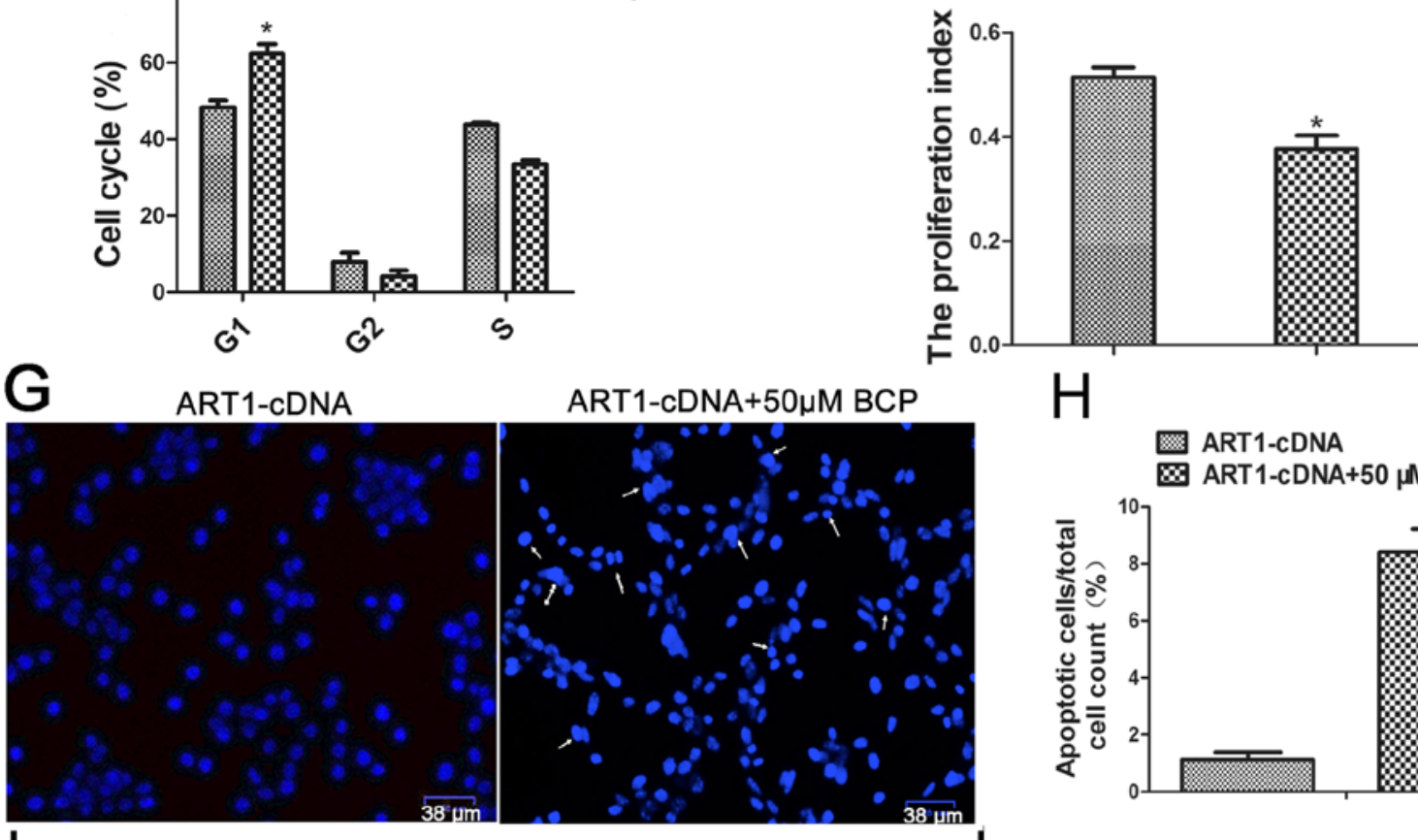

$\mathrm{H}$

I

ART1-cDNA+50 $\mu \mathrm{M}$ BCP

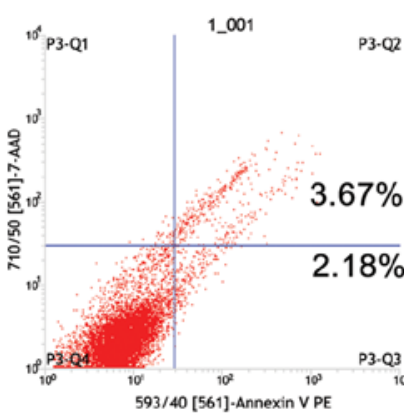

${ }_{10}^{\circ} \mathrm{P3} \cdot \mathrm{Q} 1$

1_003

P3.02

ART1-CDNA

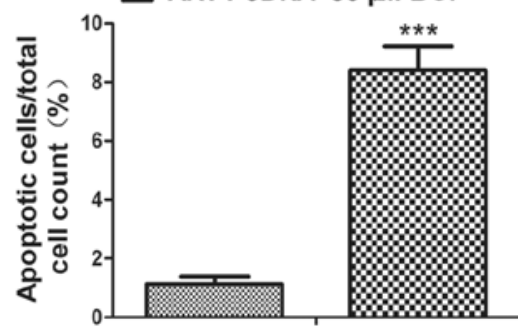

$8.64 \%$

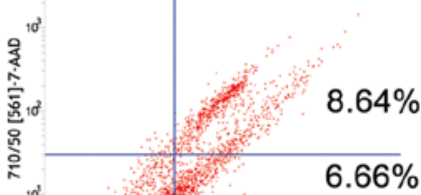

${ }_{10}^{P 3}-Q^{\circ}$

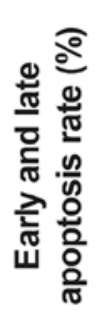

ART1-CDNA+50 $\mu \mathrm{M} B C P$

Figure 3. Effects of BCP on the proliferation, cell cycle progression and apoptosis of cells overexpressing ART1 in vitro. (A) Structure of BCP. (B and C) Cell Counting kit- 8 was used to detect the anti-proliferative effects of BCP on ART1-cDNA cells; ART1-cDNA CT26 cells were treated with BCP $(50 \mu \mathrm{M})$ for $48 \mathrm{~h}$. (D-F) Effects of BCP on the cell cycle and proliferation index of ART1-cDNA CT26 cells, as detected by flow cytometric analysis. (G and H) Hoechst 333258 staining was used to detect the number of apoptotic cells in the ART1-cDNA CT26 group in the presence or absence of BCP. The white arrows indicate apoptotic cells. (I and J) Flow cytometric analysis was used to determine the effects of BCP on the apoptosis of ART1-cDNA CT26 cells. ${ }^{*} \mathrm{P}<0.05,{ }^{* * *} \mathrm{P}<0.01$, ${ }_{* * * *}^{*}<0.001$ vs. ART1-cDNA. ART1, arginine-specific mono-ADP-ribosyltransferase 1; BCP, $\beta$-caryophyllene; DMSO, dimethyl sulfoxide. 

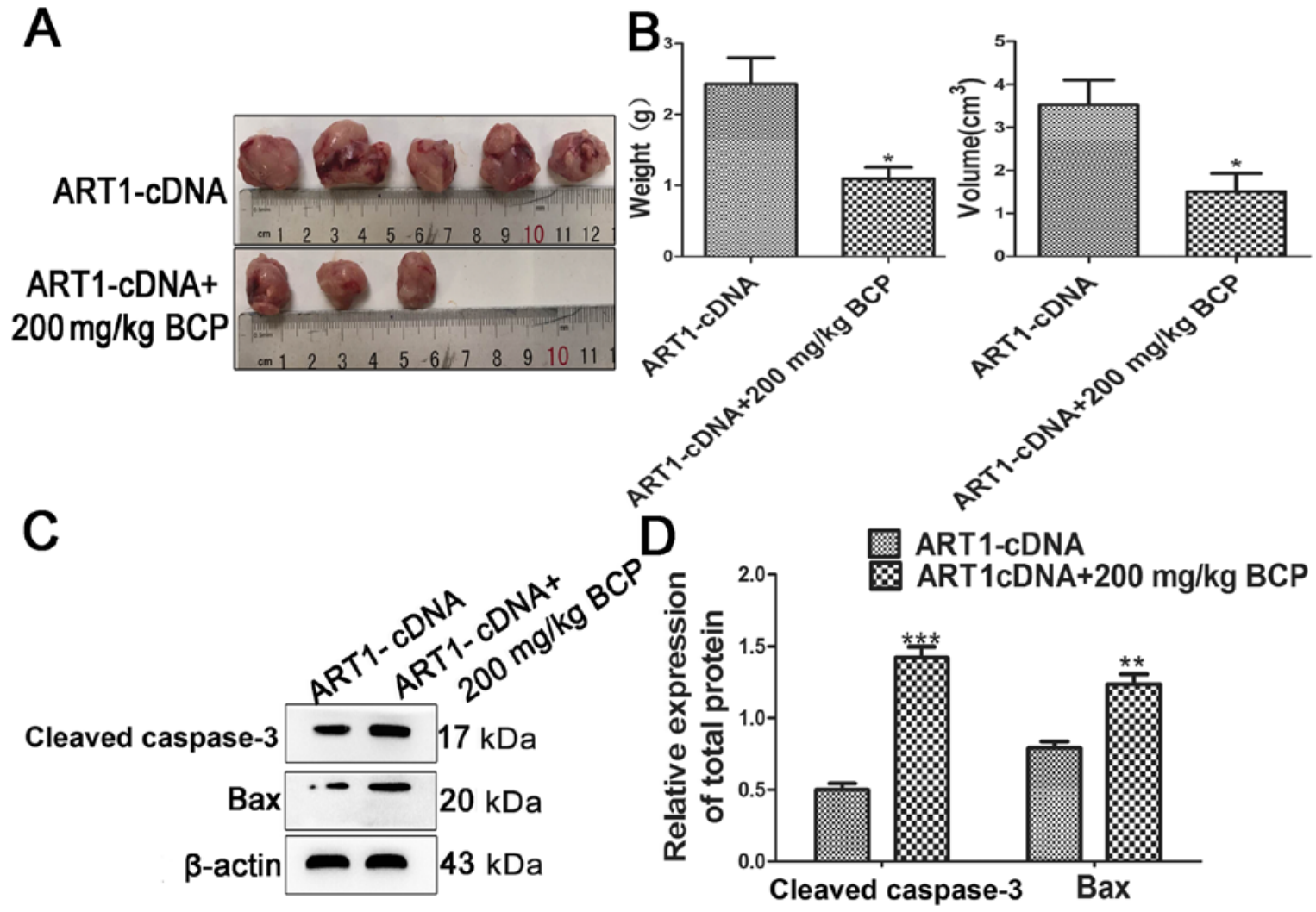

Figure 4. Effects of BCP on CT26 tumor growth and cell apoptosis in the ART1-overexpression group in vivo. (A and B) Effects of BCP on ART1-cDNA CT26 cell tumor weight and volume in diabetic Balb/c mice. (C and D) BCP upregulated the expression levels of Bax and cleaved caspase-3 in ART1-cDNA CT26 cell tumors. ${ }^{*} \mathrm{P}<0.05,{ }^{* *} \mathrm{P}<0.01,{ }^{* * * *} \mathrm{P}<0.001$ vs. ART1-cDNA group. ART1, arginine-specific mono-ADP-ribosyltransferase 1; Bax, B-cell lymphoma 2 -associated X protein; BCP, $\beta$-caryophyllene.

compared with the ART1-cDNA CT26 cells cultured without BCP $(\mathrm{P}<0.05$ Fig. 3C). Flow cytometry indicated that the proportion of ART1-cDNA CT26 cells treated with BCP in G1 phase was increased and the PI was decreased compared with the ART1-cDNA CT26 cells cultured without BCP $(\mathrm{P}<0.05$; Fig. 3D-F). Staining with Hoechst 33342 demonstrated that the number of apoptotic bodies was increased in ART1-cDNA CT26 cells treated with BCP compared with in the absence of $\mathrm{BCP}(\mathrm{P}<0.001$; Fig. $3 \mathrm{G}$ and $\mathrm{H})$. The rate of apoptosis was further analyzed by flow cytometric analysis; the apoptotic rate in ART1-cDNA CT26 cells treated with BCP $(12.88 \pm 2.53 \%)$ was higher than in ART1-cDNA CT26 cells not treated with $\mathrm{BCP}(6.7 \pm 0.845 \%)(\mathrm{P}<0.05$; Fig. 3I and J).

Effects of BCP on the growth of ART1-cDNA CT26 cell allograft transplanted tumors in diabetic Balb/c mice. BCP was dissolved in corn oil and administered intragastrically (200 mg/kg b.w.). In the ART1-cDNA + BCP group, diabetic $\mathrm{Balb} / \mathrm{c}$ mice, which were inoculated with ART1-cDNA CT26 cells for 10 days, were treated with BCP (200 mg/kg b.w.). In the control group, the same dose of corn oil was administered intragastrically to diabetic Balb/c mice, which were inoculated with ART1-cDNA CT26 cells. Tumor weight and volume were significantly decreased in the ART1-cDNA + BCP group compared with in the control group ( $\mathrm{P}<0.05$; Fig. $4 \mathrm{~A}$ and $\mathrm{B})$. Furthermore, the expression levels of apoptosis-associated proteins (Bax and cleaved caspase-3) were increased in the ART1-cDNA + BCP group compared with in the control group (Fig. 4C and D). These findings indicated that BCP may inhibit the growth and enhance the apoptotic effects of ART1 overexpression on transplanted tumors in diabetic mice.

Effects of BCP on the generation of ATP and lactic acid in ART1-cDNA CT26 cells. The intracellular ATP content and lactic acid content in the supernatant of ART1-cDNA CT26 cells treated with high glucose and BCP were assessed, in order to investigate the effects of $\mathrm{BCP}$ on aerobic glycolysis. Compared with in the untreated ART1-cDNA CT26 cells, the concentrations of ATP and lactic acid were decreased in the ART1-cDNA + BCP group (Fig. 5A and B).

Effects of BCP on the expression levels of AKT/mTOR, $c-M y c, P D K 1$ and LDHA in vivo and in vitro. The expression levels of p-AKT, p-mTOR, c-Myc, PDK1 and LDHA were all decreased in ART1-cDNA CT26 cells treated with BCP under high-glucose conditions compared with in ART1-cDNA CT26 cells cultured without $\mathrm{BCP}(\mathrm{P}<0.05$; Fig. 5C and D). Conversely, the expression levels of AKT and mTOR exhibited no significant difference between the groups $(\mathrm{P}>0.05$; Fig. $5 \mathrm{C}$ and D). Furthermore, the expression levels of p-mTOR, PDK1 and LDHA were decreased in ART1-cDNA CT26 cell tumors obtained from mice treated with BCP compared with in ART1-cDNA CT26 cell tumors obtained from untreated mice $(\mathrm{P}<0.01$; Fig. 5E and F). These findings indicated that BCP may inhibit the AKT/mTOR pathway to downregulate the levels of PDK1 and LDHA in CT26 CRC cells overexpressing ART1. 

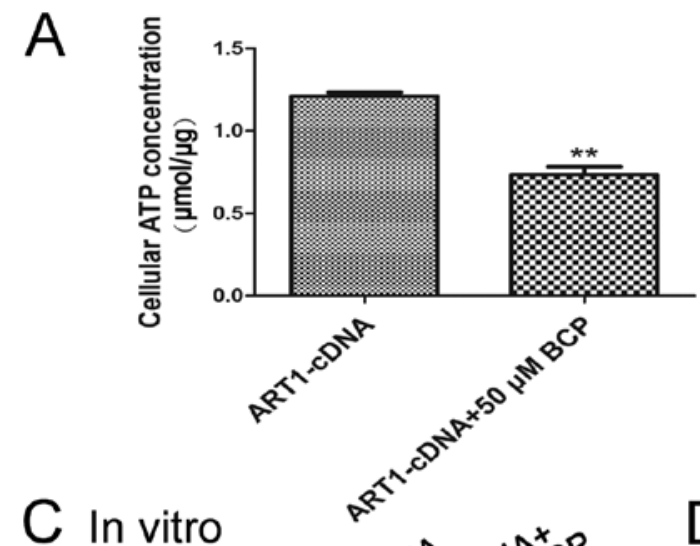

C In vitro
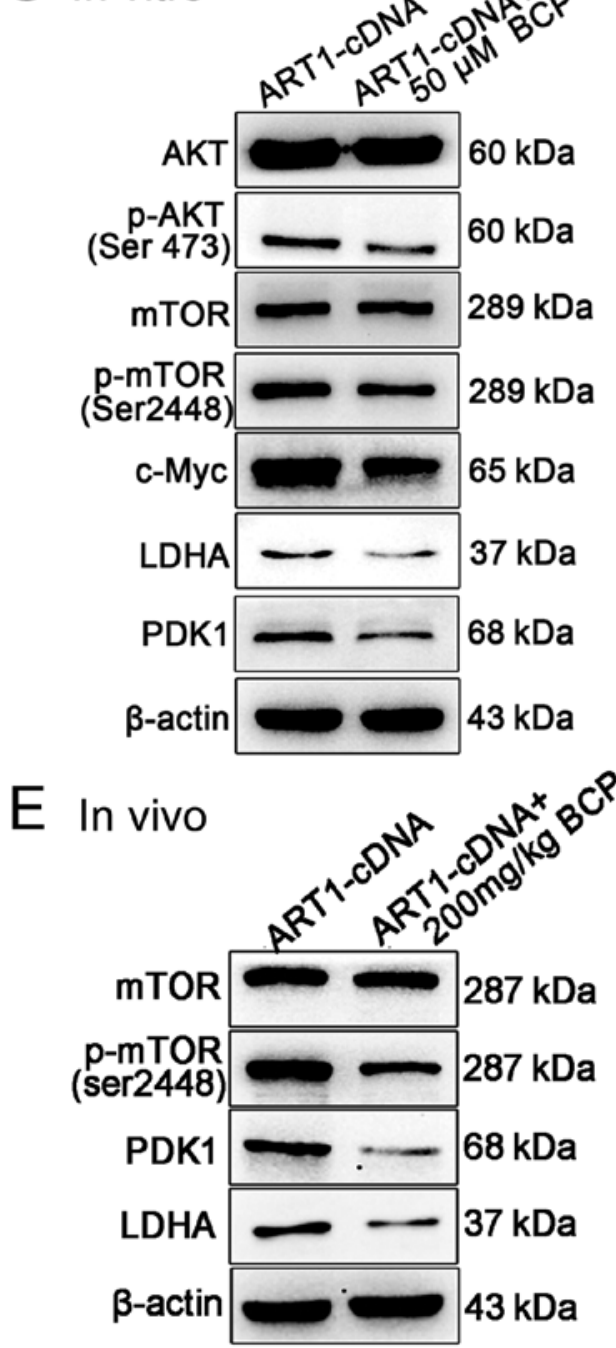
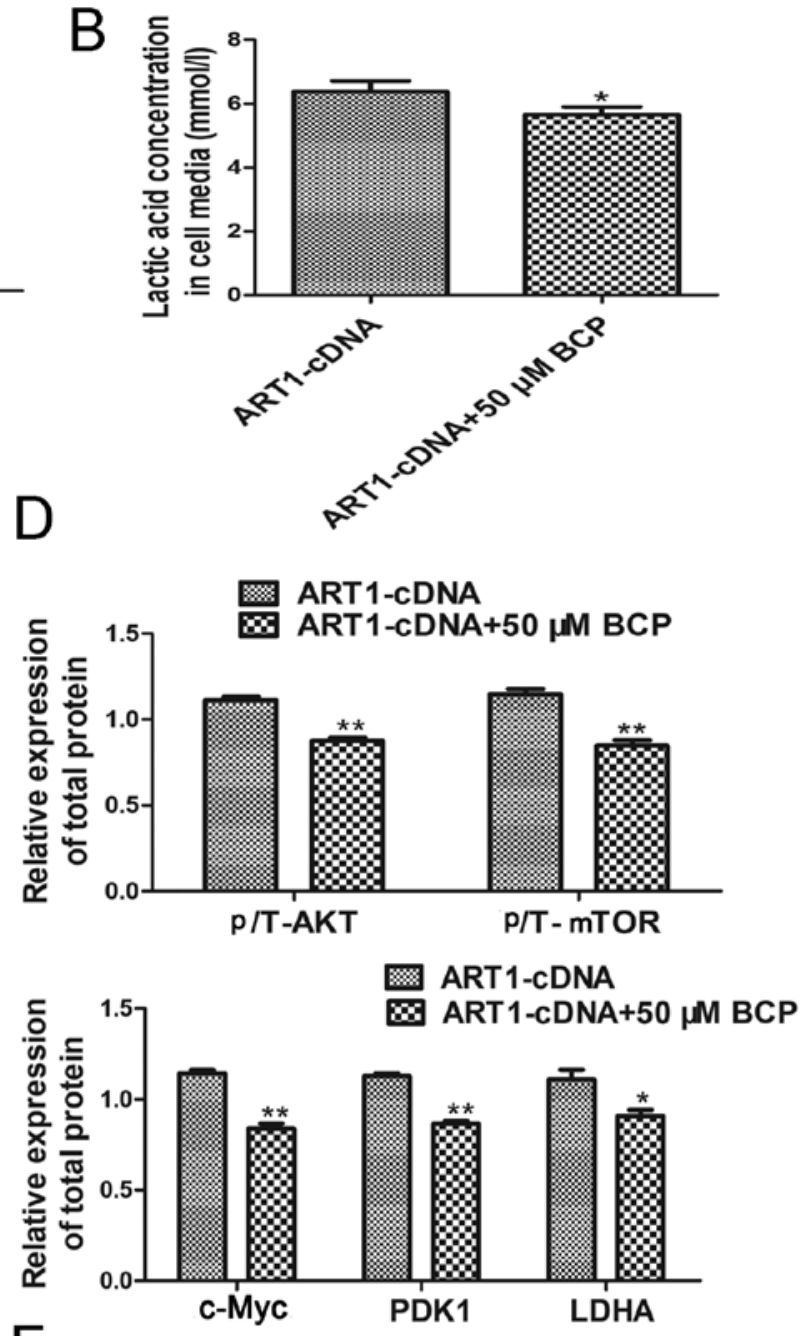

$\mathrm{F}$

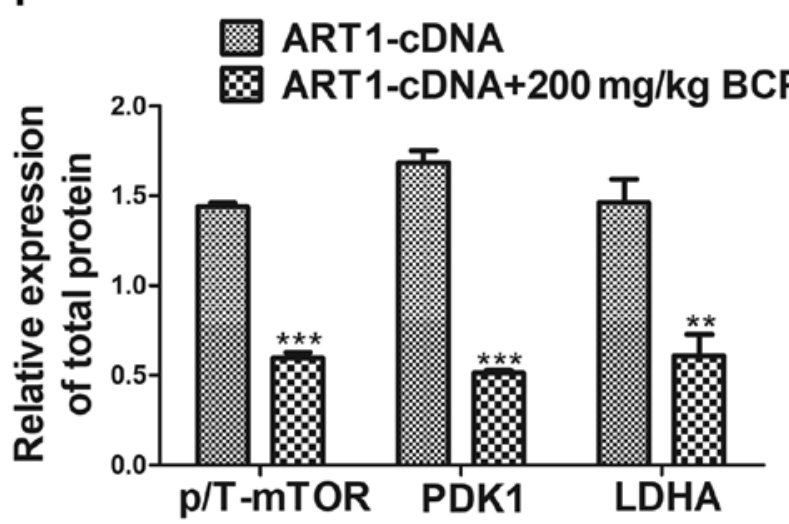

Figure 5. BCP regulates glycolysis through inhibiting the AKT/mTOR pathway. (A and B) BCP reduced the concentrations of ATP and lactic acid in ART1-cDNA CT26 cells. (C and D) Western blot analysis detected the protein expression levels of p-AKT, p-mTOR, c-Myc, PDK1 and LDHA, which were downregulated in ART1-cDNA CT26 cells treated with BCP. The protein expression levels of AKT and mTOR were not significantly different between the two groups. (E and F) Protein expression levels of p-mTOR, PDK1 and LDHA were also reduced in ART1-cDNA CT26 cell tumors from diabetic Balb/c mice treated with BCP. The protein expression level of mTOR exhibited no significant difference between the two groups. ${ }^{*} \mathrm{P}<0.05$, ${ }^{* *} \mathrm{P}<0.01,{ }^{* * *} \mathrm{P}<0.001, \mathrm{vs}$. ART1cDNA group. AKT, protein kinase B; ART1, arginine-specific mono-ADP-ribosyltransferase 1; ATP, adenosine triphosphate; BCP, $\beta$-caryophyllene; LDHA, lactate dehydrogenase; mTOR, mammalian target of rapamycin; p-, phosphorylated; PDK1, pyruvate dehydrogenase kinase 1.

$B C P$ and PDTC inhibit the expression of ART1 in CT26 cells. The present study demonstrated that the expression levels of ART1 were inhibited when ART1-cDNA CT26 cells were treated with $\mathrm{BCP}$ in vitro and in vivo $(\mathrm{P}<0.01$; Fig.6A-D); however, the underlying mechanism was unclear. It was therefore hypothesized that BCP may inhibit the expression of ART1 through regulating NF- $\mathrm{BB}$; however, to the best of our knowledge, there are no indications as to whether $\mathrm{NF}-\kappa \mathrm{B}$ can control the expression of ART1. To elucidate whether the $\mathrm{NF}-\kappa \mathrm{B}$ pathways were involved in regulating the expression of ART1, ART1-cDNA CT26 cells were treated with the NF- $\kappa$ B inhibitor, PDTC. The results demonstrated that PDTC and 


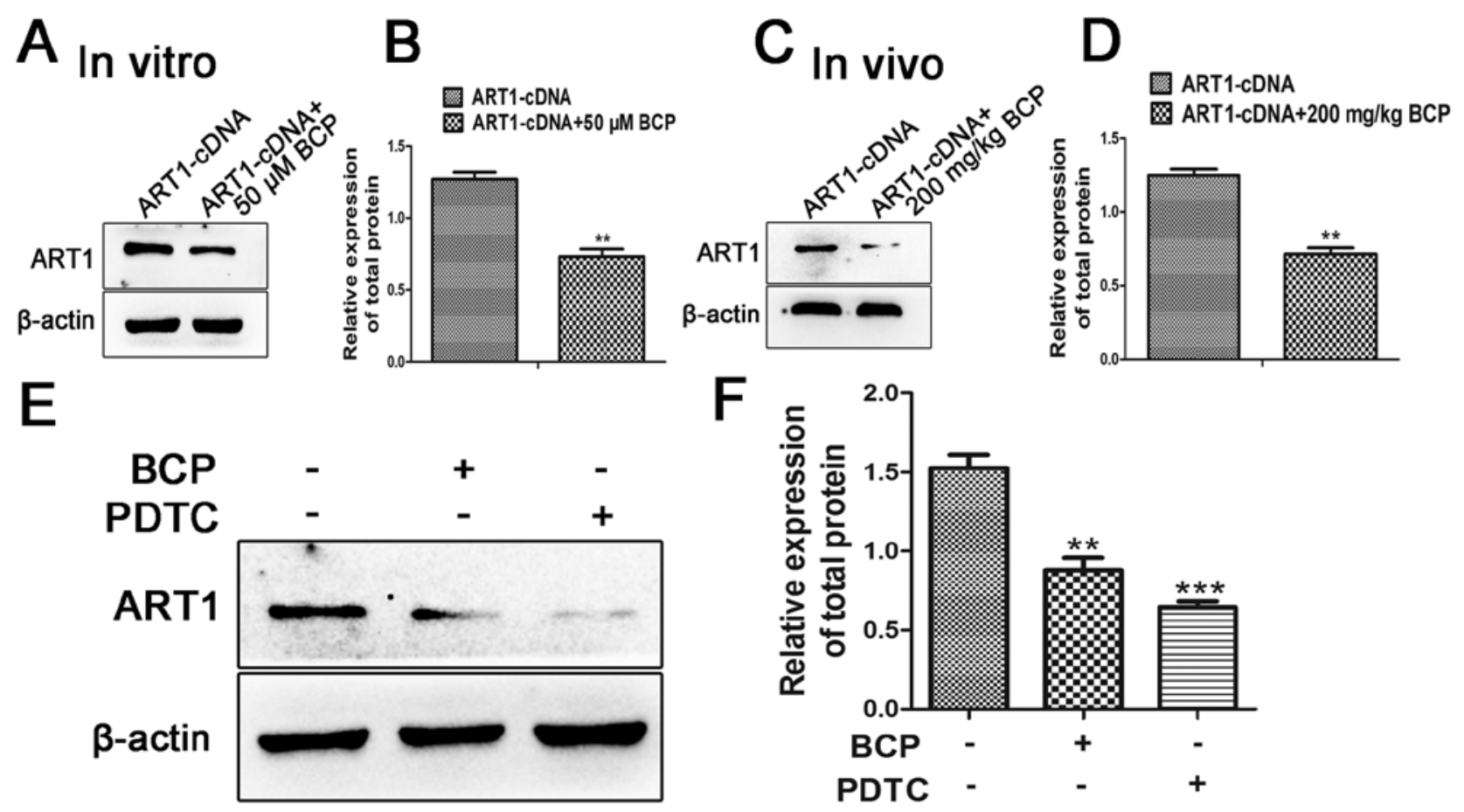

Figure 6. BCP regulates the expression levels of ART1 in CT26 cells. (A-D) ART1 expression was reduced in ART1-cDNA CT26 cells treated with BCP in vitro and in vivo. (E and F) ART1 expression was decreased in ART1-cDNA CT26 cells treated with BCP or PDT. ${ }^{* *} \mathrm{P}<0.01,{ }^{* * * *} \mathrm{P}<0.001$, vs. ART1-cDNA group. ART1, arginine-specific mono-ADP-ribosyltransferase 1; BCP, $\beta$-caryophyllene; PDTC, pyrrolidinedithiocarbamic acid.

BCP could downregulate the expression of ART1 $(\mathrm{P}<0.01$; Fig. 6E and F).

\section{Discussion}

Previous studies have demonstrated that T2DM increases the risk of CRC $(1,23,24)$. A previous meta-analysis confirmed that T2DM has a positive correlation with the risk of CRC (1). Hyperglycemia is one of the key mechanisms connecting the potential risk of cancer with diabetes (25); hyperglycemia is often associated with increases in the risk of several types of cancer $(26,27)$. A previous study revealed that only $\sim 27 \%$ of patients with CRC had normal concentrations of glucose in the blood. Furthermore, compared with in patients with normal blood glucose levels, patients with high blood glucose levels have larger tumor diameters, more poorly differentiated and aggressive tumors, and present with advanced Tumor Node Metastasis stage tumors (28). However, the mechanism underlying how high blood glucose levels contribute to the development of CRC is currently unclear. Our previous studies demonstrated that ART1 may promote the proliferation, invasion and metastasis of CRC, and inhibit the apoptosis of CRC in vitro and in vivo $(9,29)$. In addition, it was observed that the expression of ART1 in human CRC tissue from patients with T2DM is much higher than that in non-diabetic CRC tissue (Chen et al, unpublished data). The present study demonstrated that overexpression of ART1 may increase the growth of transplanted CT26 tumors in STZ-induced diabetic Balb/c mice. To confirm the effects of ART1 on aerobic glycolysis in CRC cells, the study demonstrated that ART1 could upregulate lactic acid and ATP concentrations in CT26 cells, which were cultured in a high-glucose environment. Lactic acid is a specific product of glycolysis. In addition, glucose can be oxidized to produce ATP under aerobic conditions, whereas, under anoxic conditions, ATP can be generated by glycolysis (14); therefore, both lactic acid and ATP may reveal the level of glycolysis (30). The present study indicated that ART1 may be considered a regulatory factor of glycolysis in CRC.

In our previous study, ART1 was revealed to upregulate the expression of p-AKT, c-Myc and c-Fos, in order to promote the proliferation and invasive potential of CT26 cells (9); ART1 also inhibits the apoptosis of CT26 cells via the PI3K/AKT pathway (29). A previous study demonstrated that the PI3K/AKT pathway serves a critical role in promoting aerobic glycolysis (31). AKT has also been reported to protect cancer cells from bioenergetic stress by enhancing uptake of glucose and storage of glycogen, which has a critical role in promoting the generation of ATP (32). The PI3K/ AKT/mTOR pathway is also upregulated in human diabetic nephropathy (33). Whether or not ART1 promotes glycolysis via the PI3K/AKT/mTOR pathway is currently unclear. The present study indicated that the expression levels of p-AKT and $\mathrm{p}$-mTOR were increased in the ART1 overexpression group, whereas p-AKT and p-mTOR expression levels were decreased when ART1 was downregulated. PDK1 is a key enzyme that negatively regulates the activity of the pyruvate dehydrogenase complex through phosphorylation (34). PDK1 is directly transactivated by HIF- $1 \alpha$, and HIF- $1 \alpha$ is also involved in dysregulating c-Myc to promote glycolysis (35). HIF-1 $\alpha$, which is a downstream target of mTOR, is a major transcription factor that controls cellular adaptation to hypoxia and promotes glycolytic metabolism (36). Therefore, modulation of mTOR may regulate the expression of PDK1. LDHA catalyzes the last step of anaerobic glycolysis, and 
is abnormally expressed in numerous types of human cancer $(37,38)$. Furthermore, c-Myc activates the expression of LDHA and increases production of lactate (12); it also increases the uptake of glucose by regulating LDHA and glucose transporter 1 expression $(15,39)$. In the present study, overexpression of ART1 increased the expression levels of c-Myc, PDK1 and LDHA in CT26 cells in vitro and in CT26 cell tumors in vitro, whereas the opposite effect was detected when ART1 expression was silenced. Above all, ART1 may regulate glycolysis in $\mathrm{CRC}$ through activating the AKT/mTOR pathway to upregulate the expression of c-Myc, PDK1 and LDHA.

The proliferation of MC38 colon cancer cells has been reported to be elevated and their apoptosis diminished in a T2DM environment (8). Another study observed that local IGF-1 and IGF-1R mRNA are overexpressed in T2DM patients with CRC. IGF-1 activates signaling via the PI3K/AKT/mTOR and RAS/RAF/MAPK pathways that enhance the proliferation and survival of colorectal cancer cells (40). The metabolic switch to aerobic glycolysis in cancer cells involves mTOR-mediated expression of glycolytic enzymes through the activation of HIF- $1 \alpha$, NF- $\kappa$ B and c-Myc $(41,42)$. The present study revealed that ART1 could upregulate glycolysis in CRC through activating the AKT/mTOR pathway, thus enhancing the proliferative ability and weakening the apoptosis of CT26 cells. Therefore, it is important to identify an effective and accessible drug that inhibits the AKT/mTOR pathway mediated by ART1, in order to regulate the levels of glycolysis in CRC.

$\mathrm{BCP}$ is a natural bicyclic sesquiterpene, which is found in large quantities in essential oils from cloves, cinnamon, black pepper and cannabis $(18,43)$. A previous report indicated that oral administration of BCP for 45 days decreases the concentration of glucose in the blood and increases plasma insulin; it has been reported to be more effective than glibenclamide (18). Therefore, in the present study, BCP was added to CT26 cells, which overexpressed ART1 under high glucose conditions, and to CT26 cell tumors in diabetic Balb/c mice. The results demonstrated that the concentrations of ATP and lactic acid were decreased following treatment with BCP. It was therefore suggested that BCP may affect glycolysis in ART1-overexpressing CT26 cells. Cannabinoid receptors, $\mathrm{CB} 1$ and $\mathrm{CB} 2$, are G-protein-coupled receptors and the main components of the endocannabinoid system (44). These receptors have important roles in the maintenance of the balance in energy and metabolism. BCP exclusively binds to CB2 and stimulates MAPK and PI3K signaling pathways, which in turn can activate proapoptotic proteins and inactivate anti-apoptotic proteins $(17,45)$. The present study revealed that BCP inhibited the expression of p-AKT, p-mTOR, c-Myc, PDK1 and LDHA in ART1-overexpressing CT26 cells and tumors. In CRC and pancreatic cancer cells, BCP inhibits their growth (16). Furthermore, the present study revealed that following treatment of ART1-overexpressing CT26 cells and tumors with $\mathrm{BCP}$, proliferation was reduced and apoptosis was enhanced. Therefore, it may be considered that BCP exerts a useful action on inhibiting ART1-induced glycolysis via the AKT/mTOR pathway, which may inhibit the proliferation and enhance the apoptosis of CRC cells.

The present study also aimed to determine how BCP affects ART1-induced glycolysis via the AKT/mTOR pathway. Notably, the expression of ART1 was diminished in ART1-overexpressing CT26 cells following treatment with $\mathrm{BCP}$. It is well known that AKT regulates NF- $\mathrm{B}$-dependent gene transcription and upregulates the activity of the cAMP response element binding protein $\mathrm{CR} 1 / 2$, which is necessary for the transcription of anti-apoptotic genes (45). In addition, it has been suggested that BCP binds to $\mathrm{CB} 2$ to regulate the $\mathrm{PI} 3 \mathrm{~K} / \mathrm{AKT} / \mathrm{NF}-\kappa \mathrm{B}$ pathway (44). In our previous study, it was observed that NF- $\kappa \mathrm{B}$ is inhibited by poly (ADP-ribose) polymerase 1 (PARP1) and NF- $\kappa \mathrm{B}$ was revealed to inhibit PARP1 by negative feedback in LoVo cells (46). It has also been observed that ART1 inhibits the expression of PARP1 in CT26 cells (19). Some researchers consider mono-ADP-ribosylation to be the basis of poly-(ADP-ribosy)lation; the addition of more than one ADP-ribose units to a mono-ADP-ribosylated molecule may result in the initiation of poly-(ADP-ribosy)lated modification $(47,48)$. ART1 and PARP1, which are catalyzing enzymes of mono-ADP-ribosylation and poly-ADP-ribosylation respectively, are closely connected in CRC. Therefore, it was hypothesized that NF- $\kappa \mathrm{B}$ may also regulate the expression of ART1; to the best of our knowledge, no previous study has reported this. To explore this, PDTC (an inhibitor of NF- $\mathrm{B}$ ) was added to ART1-overexpressing CT26 cells; the expression levels of ART1 were decreased following treatment with PDTC. Therefore, inhibition of $\mathrm{NF}-\kappa \mathrm{B}$ may downregulate the expression of ART1. These findings suggested that BCP may inhibit ART1-induced glycolysis via the AKT/mTOR pathway, possibly through the downregulation of $\mathrm{NF}-\kappa \mathrm{B}$, which may decrease the expression of ART1. However, exactly how $\mathrm{NF}-\kappa \mathrm{B}$ regulates the expression of ART1 requires further study.

In conclusion, the present study revealed that, in CRC cells, ART1 may increase the generation of ATP and lactic acid by upregulating the AKT/mTOR/c-Myc pathway, thus increasing the expression of PKD1 and LDHA, and affecting the proliferation and apoptosis of CT26 cells under high-glucose conditions. Conversely, the plant product BCP inhibited ART1-induced glycolysis through the AKT/mTOR pathway, which could suppress the proliferation and enhance the apoptosis of CRC cells. Therefore, ART1 may have an important role in glycolysis in $\mathrm{CRC}$, and is proposed as a therapeutic target for the treatment of diabetic patients with CRC. Furthermore, BCP may be considered an important lead for the identification of novel drugs for the treatment of diabetic patients with CRC.

\section{Acknowledgements}

The authors would like to thank Professor YQ Wei (Sichuan University, Chengdu, China) for his gift of the CT26 cell line. Sincere thanks to Professor Michael D. Threadgill (Department of Pharmacy and Pharmacology, University of Bath) who performed language editing to improve language skills of the article.

\section{Funding}

The present study was supported by the Innovation Project of Graduate Student in Chongqing (grant no. CYS16120); the Scientific Research Foundation of Chongqing Medical 
University (grant no. 201413); the National Nature Science Foundation of China (grant no. 30870946); the Science and Technology Plan Project of Yuzhong District in Chongqing (grant no. 20140106); and the National High Technology Research and Development Program of China (grant no. 2012AA02A201).

\section{Availability of data and materials}

The datasets used and/or analyzed during the current study are available from the corresponding author on reasonable request.

\section{Author contributions}

LZ performed experiments, analyzed the data and wrote the manuscript. MLZ helped to construct the animal model and participated in the experiment to detect protein expression levels in CT26 cells. YT conducted several experiments and edited the manuscript. YLW designed and conducted the experiments. MX designed and modified the figures. ML analyzed and interpreted the data. QSL performed the Hoechst 33258 staining. LY performed the flow cytometric analysis. XL detected the concentrations of lactic acid and ATP. WWC participated in the construction of the transplanted tumor model in diabetic Balb/c mice.

\section{Ethics approval and consent to participate}

The present study was approved by the ethics committee of Chongqing Medical University (Chongqing, China).

\section{Patient consent for publication}

Not applicable.

\section{Competing interests}

The authors declare that they have no competing interests.

\section{References}

1. Guraya SY: Association of type 2 diabetes mellitus and the risk of colorectal cancer: A meta-analysis and systematic review. World J Gastroenterol 21: 6026-6031, 2015.

2. Yu F, Guo Y, Wang H, Feng J, Jin Z, Chen Q, Liu Y and He J: Type 2 diabetes mellitus and risk of colorectal adenoma: A metaanalysis of observational studies. BMC Cancer 16: 642, 2016.

3. Xu HL, Fang H, Xu WH, Qin GY, Yan YJ, Yao BD, Zhao NQ, Liu YN, Zhang F, Li WX, et al: Cancer incidence in patients with type 2 diabetes mellitus: A population-based cohort study in Shanghai. BMC Cancer 15: 852, 2015.

4. Mills KT, Bellows CF, Hoffman AE, Kelly TN and Gagliardi G: Diabetes mellitus and colorectal cancer prognosis: A metaanalysis. Dis Colon Rectum 56: 1304-1319, 2013.

5. Duan W, Shen X, Lei J, Xu Q, Yu Y, Li R, Wu E and Ma Q: Hyperglycemia, a neglected factor during cancer progression. BioMed Res Int 2014: 461917, 2014.

6. Masur K, Vetter C, Hinz A, Tomas N, Henrich H, Niggemann B and Zänker KS: Diabetogenic glucose and insulin concentrations modulate transcriptome and protein levels involved in tumour cell migration, adhesion and proliferation. Br J Cancer 104: 345-352, 2011.

7. Shin HY, Jung KJ, Linton JA and Jee SH: Association between fasting serum glucose levels and incidence of colorectal cancer in Korean men: The Korean Cancer Prevention Study-II. Metabolism 63: 1250-1256, 2014.
8. Teng JA, Wu SG, Chen JX, Li Q, Peng F, Zhu Z, Qin J and He ZY: The activation of ERK1/2 and JNK MAPK signaling by insulin/ IGF-1 is responsible for the development of colon cancer with type 2 diabetes mellitus. PLoS One 11: e0149822, 2016.

9. Xu JX, Xiong W, Zeng Z, Tang Y, Wang YL, Xiao M, Li M, Li QS, Song GL and Kuang J: Effect of ART1 on the proliferation and migration of mouse colon carcinoma CT26 cells in vivo. Mol Med Rep 15: 1222-1228, 2017.

10. Song GL, Jin CC, Zhao W, Tang Y, Wang YL, Li M, Xiao M, Li X, Li QS, Lin X, et al: Regulation of the RhoA/ROCK/AKT/ $\beta$ catenin pathway by arginine-specific ADP-ribosytransferases 1 promotes migration and epithelial-mesenchymal transition in colon carcinoma. Int J Oncol 49: 646-656, 2016.

11. Yang L, Xiao M, Li X, Tang Y and Wang YL: Arginine ADP-ribosyltransferase 1 promotes angiogenesis in colorectal cancer via the PI3K/Akt pathway. Int J Mol Med 37: 734-742, 2016.

12. He TL, Zhang YJ, Jiang H, Li XH, Zhu H and Zheng KL: The c-Myc-LDHA axis positively regulates aerobic glycolysis and promotes tumor progression in pancreatic cancer. Med Oncol 32: $187,2015$.

13. Jeoung NH: Pyruvate dehydrogenase kinases: Therapeutic targets for diabetes and cancers. Diabetes Metab J 39: 188-197, 2015.

14. Gatenby RA and Gillies RJ: Why do cancers have high aerobic glycolysis? Nat Rev Cancer 4: 891-899, 2004.

15. Wahlström T and Henriksson MA: Impact of MYC in regulation of tumor cell metabolism. Biochim Biophys Acta 1849: 563-569, 2015.

16. Dahham SS, Tabana YM, Iqbal MA, Ahamed MB, Ezzat MO, Majid AS and Majid AM: The anticancer, antioxidant and antimicrobial properties of the sesquiterpene $\beta$-caryophyllene from the essential oil of Aquilaria crassna. Molecules 20: 11808-11829, 2015.

17. Demuth DG and Molleman A: Cannabinoid signalling. Life Sci 78: 549-563, 2006.

18. Basha RH and Sankaranarayanan C: $\beta$-caryophyllene, a natural sesquiterpene, modulates carbohydrate metabolism in streptozotocin-induced diabetic rats. Acta Histochem 116: 1469-1479, 2014.

19. Tang Y, Wang YL, Yang L, Xu JX, Xiong W, Xiao M and $\mathrm{Li} \mathrm{M}$ : Inhibition of arginine ADP-ribosyltransferase 1 reduces the expression of poly(ADP-ribose) polymerase-1 in colon carcinoma. Int J Mol Med 32: 130-136, 2013.

20. Kuang J, Wang YL, Xiao M, Tang Y, Chen WW, Song GL, Yang $\mathrm{X}$ and Li M: Synergistic effect of arginine-specific ADP-ribosyltransferase 1 and poly(ADP-ribose) polymerase-1 on apoptosis induced by cisplatin in CT26 cells. Oncol Rep 31: 2335-2343, 2014.

21. Leontieva OV,Demidenko ZN and Blagosklonny MV: Rapamycin reverses insulin resistance (IR) in high-glucose medium without causing IR in normoglycemic medium. Cell Death Dis 5: e1214, 2014.

22. Cheng W, Wu P, Du Y, Wang Y, Zhou N, Ge Y and Yang Z: Puerarin improves cardiac function through regulation of energy metabolism in Streptozotocin-Nicotinamide induced diabetic mice after myocardial infarction. Biochem Biophys Res Commun 463: 1108-1114, 2015.

23. De Bruijn KMJ, Arends LR, Hansen BE, Leeflang S, Ruiter R and van Eijck CH: Systematic review and meta-analysis of the association between diabetes mellitus and incidence and mortality in breast and colorectal cancer. Br J Surg 100: 1421-1429, 2013.

24. Wang M, Hu RY, Wu HB, Pan J, Gong WW, Guo LH, Zhong JM, Fei FR and Yu M: Cancer risk among patients with type 2 diabetes mellitus: A population-based prospective study in China. Sci Rep 5: $11503,2015$.

25. García-Jiménez C, García-Martínez JM, Chocarro-Calvo A and De la Vieja A: A new link between diabetes and cancer: Enhanced WNT/ $\beta$-catenin signaling by high glucose. J Mol Endocrinol 52: R51-R66, 2013.

26. Lin CY, Lee CH, Huang CC, Lee ST, Guo HR and Su SB: Impact of high glucose on metastasis of colon cancer cells. World J Gastroenterol 21: 2047-2057, 2015.

27. Takatani-Nakase T, Matsui C, Maeda S, Kawahara S and Takahashi K: High glucose level promotes migration behavior of breast cancer cells through zinc and its transporters. PLoS One 9: e90136, 2014.

28. Cui G, Zhang T, Ren F, Feng W-M, Yao Y, Cui J, Zhu G-L and Shi Q-L: High blood glucose levels correlate with tumor malignancy in colorectal cancer patients. Med Sci Monit 21: 3825-3833, 2015. 
29. Xiao M, Tang Y, Wang YL, Yang L, Li X, Kuang J and Song GL: ART1 silencing enhances apoptosis of mouse CT26 cells via the PI3K/Akt/NF-kB pathway. Cell Physiol Biochem 32: 1587-1599, 2013.

30. Seyfried TN and Shelton LM: Cancer as a metabolic disease. Nutr Metab (Lond) 7: 7, 2010.

31. Vazquez A, Liu J, Zhou Y and Oltvai ZN: Catabolic efficiency of aerobic glycolysis: The Warburg effect revisited. BMC Syst Biol 4: $58,2010$.

32. Cheng KW, Agarwal R, Mitra S, Lee JS, Carey M, Gray JW and Mills GB: Rab25 increases cellular ATP and glycogen stores protecting cancer cells from bioenergetic stress. EMBO Mol Med 4: 125-141, 2012.

33. Kume S, Thomas MC and Koya D: Nutrient sensing, autophagy, and diabetic nephropathy. Diabetes 61: 23-29, 2012.

34. Sun W, Xie Z, Liu Y, Zhao D, Wu Z, Zhang D, Lv H, Tang S, Jin $\mathrm{N}$, Jiang $\mathrm{H}$, et al: JX06 Selectively inhibits pyruvate dehydrogenase kinase PDK1 by a covalent cysteine modification. Cancer Res 75: 4923-4936, 2015.

35. Kim JW, Gao P, Liu YC, Semenza GL and Dang CV: Hypoxiainducible factor 1 and dysregulated c-Myc cooperatively induce vascular endothelial growth factor and metabolic switches hexokinase 2 and pyruvate dehydrogenase kinase 1 . Mol Cell Biol 27: 7381-7393, 2007.

36. Sun Q, Chen X, Ma J, Peng H, Wang F, Zha X, Wang Y, Jing Y, Yang $\mathrm{H}$, Chen R, et al: Mammalian target of rapamycin up-regulation of pyruvate kinase isoenzyme type M2 is critical for aerobic glycolysis and tumor growth. Proc Natl Acad Sci USA 108: 4129-4134, 2011

37. Sheng SL, Liu JJ, Dai YH, Sun XG, Xiong XP and Huang G: Knockdown of lactate dehydrogenase A suppresses tumor growth and metastasis of human hepatocellular carcinoma. FEBS J 279 3898-3910, 2012

38. Shi M, Cui J, Du J, Wei D, Jia Z, Zhang J, Zhu Z, Gao Y and $\mathrm{X}$ ie $\mathrm{K}$ : A novel KLF4/LDHA signaling pathway regulates aerobic glycolysis in and progression of pancreatic cancer. Clin Cancer Res 20: 4370-4380, 2014.
39. Broecker-Preuss M, Becher-Boveleth N, Bockisch A, Dührsen U and Müller S: Regulation of glucose uptake in lymphoma cell lines by c-MYC- and PI3K-dependent signaling pathways and impact of glycolytic pathways on cell viability. J Transl Med 15: $158,2017$.

40. Liu R, Hu LL, Sun A, Cao YJ, Tang T, Zhang XP and Zhang QH: mRNA expression of IGF-1 and IGF-1R in patients with colorectal adenocarcinoma and type 2 diabetes. Arch Med Res 45: 318-324, 2014.

41. Csibi A and Blenis J: Appetite for destruction: The inhibition of glycolysis as a therapy for tuberous sclerosis complex-related tumors. BMC Biol 9: 69, 2011.

42. Düvel K, Yecies JL, Menon S, Raman P, Lipovsky AI, Souza AL, Triantafellow E, Ma Q, Gorski R, Cleaver S, et al: Activation of a metabolic gene regulatory network downstream of mTOR complex 1. Mol Cell 39: 171-183, 2010.

43. Yassa HD and Tohamy AF: Extract of Moringa oleifera leaves ameliorates streptozotocin-induced Diabetes mellitus in adult rats. Acta Histochem 116: 844-854, 2014.

44. Brown I, Cascio MG, Rotondo D, Pertwee RG, Heys SD and Wahle KW: Cannabinoids and omega-3/6 endocannabinoids as cell death and anticancer modulators. Prog Lipid Res 52: 80-109, 2013.

45. Hussain AR, Ahmed SO, Ahmed M, Khan OS, Al Abdulmohsen S, Platanias LC, Al-Kuraya KS and Uddin S: Cross-talk between NFkB and the PI3-kinase/AKT pathway can be targeted in primary effusion lymphoma (PEL) cell lines for efficient apoptosis. PLoS One 7: e39945, 2012.

46. Pan J, Fauzee NJ, Wang YL, Sheng YT, Tang Y, Wang JQ, Wu WQ, Yan JX and Xu J: Effect of silencing PARG in human colon carcinoma LoVo cells on the ability of HUVEC migration and proliferation. Cancer Gene Ther 19: 715-722, 2012.

47. Boulikas T: At least 60 ADP-ribosylated variant histones are present in nuclei from dimethylsulfate-treated and untreated cells. EMBO J 7: 57-67, 1988.

48. Burzio LO, Riquelme PT and Koide SS: ADP ribosylation of rat liver nucleosomal core histones. J Biol Chem 254: 3029-3037, 1979. 